\title{
PREVALENCE OF COUGH OF MORE THAN TWO WEEKS IN A RURAL PANCHAYATH AREA IN TRIVANDRUM DISTRICT - A CROSS SECTIONAL SURVEY
}

Benny P.V1, Manojan K.K², Anil Bindu S³, Regi Jose ${ }^{4}$

HOW TO CITE THIS ARTICLE:

Benny PV, Manojan KK, Anil Bindu S, Regi Jose. "Prevalence of cough of more than two weeks in a rural panchayath area in Trivandrum district - a cross sectional survey". Journal of Evolution of Medical and Dental Sciences 2013; Vol. 2, Issue 40, October 07; Page: 7781-7784.

ABSTRACT: BACKGROUND: Case detection is based on identification of TB suspects attending health facilities and subjecting them to sputum examination in a RNTCP Designated Microscopy Centre (DMC). Any patient presenting with cough for more than 2 weeks is a pulmonary TB suspect and is to be referred to the DMC. In a peripheral health institution (PHI) of rural setting, it is expected that at least $2 \%$ of new adult out patients are chest symptomatic (pulmonary TB suspects). There is paucity of data regarding the prevalence of cough for more than 2 weeks in community. Objective: To determine the prevalence of cough for more than 2 weeks in a rural community. Materials and Methods: This is a cross sectional study conducted among 239 households in Kallara panchayath in Thiruvananthapuram district Kerala. Results: The prevalence of cough for more than 2 weeks was found to $13.8 \%$, with highest prevalence among the age group of 45 to 60 years. Conclusion: Prevalence of cough for more than 2 weeks in the community is high and need more activities to encouraged sputum to be tested to rule out pulmonary tuberculosis.

BACKGROUND: As per the World Health Organization (WHO) global TB control report 2011, India continues to bear the highest global burden of TB with an estimated 2.3 million incident cases per annum accounting for more than one-fourth of global TB incidence (1). The cough is the major symptom of pulmonary tuberculosis, subjects with coughs contributed $69.5 \%$ (2). Case detection is based on identification of TB suspects attending health facilities and subjecting them to sputum examination in a RNTCP Designated Microscopy Centre (DMC). Any patient presenting with cough for more than 2 weeks is a pulmonary TB suspect and is to be referred to the DMC (3). In a peripheral health institution (PHI) of rural setting, it is expected that at least $2 \%$ of new adult out patients are chest symptomatic (pulmonary TB suspects). It is expected that on an average $5-15 \%$ of the chest symptomatic subjected for sputum examination are found to be sputum smear positive following standard operating procedures of ZN staining (4). The yield of sputum positive cases is not much changed when more than two weeks of cough and more than three weeks of cough were compared, $9.4-11.1 \%$ for 2 weeks against $11.3-13.5 \%$ for 3 weeks (5). Usually these chests symptomatic are identified from patients attending general outpatient departments. If we examine 10 patients with cough of two weeks or more duration, it is supposed to identify one smear positive pulmonary tuberculosis. Based on the annual risk of infection (ARI), it is expected that at least 2 to $4 \%$ of the patient attending the general OPDs are chest symptomatic. The load of chest symptomatic in community; is still not clear, because of the varying health seeking behavior and use of alternative systems of medicine in rural areas. This study assesses the prevalence of cough for more than 2 weeks in a rural community, where lot of alternative systems exists for cough management.

MATERIALS AND METHOD: This study was conducted in a rural panchayath in Kerala, Kallara which is a field practicing area of Sree Gokulam Medical College. This was a cross sectional survey 


\section{ORIGINAL ARTICLE}

conducted during the period from July to August 2013. The study participants in this study were 239 people above the age five years who were the permanent residents of Kallara Panchayath. The sample size calculation was not done due to the limited times for this study. From each house one member was selected randomly and interviewed using a questionnaire after taking informed consent. Study variables include age, sex, education \& history of cough more than two weeks within the past six months. Those with chronic cough diagnosed as some other respiratory disorder, and is on treatment were excluded from this study. The questionnaire was translated in local language for easy understanding and the data were tabulated in MS excel 2007 software and analyzed using the statistical software SPSS.16.

RESULTS: Of the total 239 people $23.8 \%$ were children(14 years or below) $44.8 \%$ were in the age group of 15 to 44 years, $15.9 \%$ were those within the age of 45 to 60 years, and $15.5 \%$ belonged to the age group of $>60$ years. $51.9 \%$ of the study participants were females. The majority of them, $30.5 \%$ belonged to just literate group and $14.2 \%$ belonged to illiterate group (Table 1). This literacy status is because of the inclusion of children in study subjects. Among the study subjects, $26.8 \%$ were unemployed and $24.7 \%$ were students.

The prevalence of at least one episode of cough for more than 2 weeks within the past six months was $13.8 \%$ (Table 2). One of the major finding in this study is that those within the age group of 45 to 60 years ;28.9\% suffered from cough for more than 2 weeks, and those above the age of 60 years $27 \%$ had it within the past six months.(Table 3 ).

Out of the 33 patients with cough of more than two weeks duration, only 7 (31.8\%) have undergone sputum examination for the diagnosis of pulmonary tuberculosis.

DISCUSSION: The six month period prevalence of cough for more than 2 weeks in this study was 13.8\% which is much higher than the expected prevalence based on Annual risk of Infection (ARI). This prevalence was much higher than the previous prevalence of cough of more than three weeks duration obtained from a study conducted in Trivandrum Corporation area in 2004 (6). A much higher prevalence in the age group of 45 to 60 years and $>60$ years may be due to some seasonal influence in the last six months period. The prevalence of cough in children is $5.26 \%$ which is comparable to the expected estimate for the State of Kerala. In another study, the patients seen by OPD medical assistants, 438 (18.4\%) complained of cough: 303 for $<3$ weeks and 135 for $>$ or $=3$ weeks (7). The sputum referral for AFB staining was also very poor; so a community oriented active screening of chest symptomatic for tuberculosis, and prompt referral for sputum examination may be suggested as the strategy to improve the case finding in Revised National Tuberculosis control programme.

CONCLUSION: Prevalence of cough for more than 2 weeks in the community is high and need more activities to encouraged sputum to be tested to rule out pulmonary tuberculosis. The activity should be mainly oriented to enhance the knowledge regarding pulmonary tuberculosis and importance of sputum testing. 


\section{BIBLIOGRAPHY:}

1. HealthOrganization, World. World Health report, Global Tuberculosis Control. Geneva : s.n., 2011. World Health Report.

2. Evaluation of different types of chest symptoms for diagnosing pulmonary tuberculosis cases in community surveys. Gopi PG, Subramani R, Narayanan PR. 3, Chennai-600 031, India : s.n., July 2008, Indian J Tuberc, Vol. 55, pp. 116-21.

3. India, Government of. TB India 2013, Revised National Tuberculosis Control Programme, Annual Repor. Central TB division. New Delhi : s.n., 2013. p. www.tbcindia.nic.in., Annual Report.

4. RNTCP. Mananging RNTCP in your area, Module 1 to 4. Central TB Division. New Delhi : s.n., 2012. p. Module 1 to 4.

5. al, GVJ Baily et. Bull WHO37. Geneva : WHO, 1967. pp. 875-892.(22).

6. PV, Benny. A study on problems associated with case detection of pulmonary tuberculosis in Thiruvananthapuram corporation area.Trivandrum. 2004. Unpublished MD thesis work, university of Kerala.

7. Case finding for pulmonary tuberculosis, Queen Elizabeth Central Hospital, Blantyre, Malawi. Harries AD, Kamenya. 1(6), Blantyre : Int J Tuberc Lung Dis, 1997 Dec, Vols. 523-7.

\section{TABLES:}

\begin{tabular}{|c|c|c|}
\hline Educational status & Frequency & Percent \\
\hline Illiterate & 34 & 14.2 \\
\hline Just literate & 73 & 30.5 \\
\hline Primary school & 56 & 23.4 \\
\hline High/higher secondary school & 43 & 18.0 \\
\hline College & 20 & 8.4 \\
\hline Professional & 13 & 5.4 \\
\hline Total & 239 & 100.0 \\
\hline
\end{tabular}

Table 1: Educational Status

\begin{tabular}{|c|c|c|}
\hline Cough of 2 weeks or more & Frequency & Percent \\
\hline Yes & 33 & 13.8 \\
\hline No & 206 & 86.2 \\
\hline Total & 239 & 100.0 \\
\hline
\end{tabular}

Table 2: Prevalence of cough for more than 2 weeks 


\section{ORIGINAL ARTICLE}

\begin{tabular}{|c|c|c|c|c|}
\hline \multirow{2}{*}{ Age group in years } & \multicolumn{2}{|c|}{ COUGH $>2$ WKS } & \multirow{2}{*}{$\begin{array}{c}\text { Yes } \\
\text { (Percent) }\end{array}$} & Total \\
\hline Yes & 3 & 54 & 5.26 & 57 \\
\hline$<15 y$ No & 9 & 98 & 8.41 & 107 \\
\hline $15-45 y r s$ & 11 & 27 & 28.94 & 38 \\
\hline $46-60 y r s$ & 10 & 27 & 27.03 & 37 \\
\hline$>60$ years & 33 & 206 & 13.81 & 239 \\
\hline Total & Table 3: Age wise prevalence of cough for more than 2 weeks \\
\hline
\end{tabular}

\section{AUTHORS:}

1. Benny P.V.

2. Manojan K.K.

3. Anil Bindu S.

4. Regi Jose

\section{PARTICULARS OF CONTRIBUTORS:}

1. Associate Professor, Department of Community Medicine, Sree Gokulam Medical College, Venjaramoodu, Trivandrum.

2. Associate Professor, Department of General Medicine, Sree Gokulam Medical College, Venjaramoodu, Trivandrum.

3. Associate Professor, Department of Community Medicine, Sree Gokulam Medical College, Venjaramoodu, Trivandrum.
4. Associate Professor, Department of Community Medicine, Sree Gokulam Medical College, Venjaramoodu, Trivandrum.

\section{NAME ADDRESS EMAIL ID OF THE}

\section{CORRESPONDING AUTHOR:}

Dr. Benny P.V.

Ashirvad, TC-2/1997(1),

Kulathoor. PO,

Trivandrum, Kerala.

PIN - 695583.

Email -drbennytvm@gmail.com

Date of Submission: 24/09/2013.

Date of Peer Review: 25/09/2013.

Date of Acceptance: 01/10/2013.

Date of Publishing: 07/10/2013 